\title{
Simulation of Sugarcane Growth and Yield Under Optimized Subsurface Irrigation System
}

M.H.J.P. Gunarathna ( $\square$ janaka78@agri.rjt.ac.lk)

Rajarata University of Sri Lanka

M.K.N. Kumari

Rajarata University of Sri Lanka

\section{Research Article}

Keywords: calibration, irrigation water use, OPSIS, parameterization, soil moisture dynamics, validation

Posted Date: May 13th, 2021

DOI: https://doi.org/10.21203/rs.3.rs-509091/v1

License: (c) (i) This work is licensed under a Creative Commons Attribution 4.0 International License. Read Full License 
1 Simulation of sugarcane growth and yield under optimized subsurface irrigation system

2 M.H.J.P. Gunarathna ${ }^{1^{*}}$ and M.K.N. Kumari ${ }^{1}$

$3 \quad{ }^{1}$ Faculty of Agriculture, Rajarata University of Sri Lanka, Puliyankulama, Anuradhapura 50000, Sri Lanka

4 https://orcid.org/0000-0002-3961-3600 (M.H.J.P.G.); https://orcid.org/0000-0002-7612-3205 (M.K.N.K)

5 janaka78@agri.rjt.ac.lk (M.H.J.P.G.); nadeeka@agri.rjt.ac.lk (M.K.N.K.)

6 Tel.: +94-71-8665585 (M.H.J.P.G.); Tel.: +94-71-7511718 (M.K.N.K.)

7 *Correspondence: janaka78@agri.rjt.ac.lk (M.H.J.P.G.)

9 Abstract:

10 The optimized subsurface irrigation system (OPSIS) is a newly developed subsurface irrigation system to irrigate

11 upland crops. Although it is already evaluated for few crops using field experiments, further evaluation is required.

12 Since field experiments are tedious, expensive, we need an alternative approach to evaluate the OPSIS. A well-

13 calibrated and validated crop model is a fast-alternative option for developing and evaluating agronomic practices.

14 Therefore, this study aimed to develop the modeling capabilities of APSIM to simulate the OPSIS. We conducted

15 field experiments for three growing seasons (main crop and two ratoons), two planting seasons (spring and summer

16 planting), and two separate crops to collect necessary data for calibration and validation processes. We scripted a

17 new module named "OPSIS" to couple OPSIS to the APSIM engine. We parameterized, calibrated, and validated

18 the APSIM to simulate the growth and yield of sugarcane with OPSIS. After firm parameterization and calibration,

19 APSIM-Sugar can successfully simulate the growth and yield of sugarcane with OPSIS. However, the simulation 
of soil moisture dynamics and irrigation water use were not up to the standards. Although it gives quite reasonable

21 results for growth and yield simulations of sugarcane, further studies are suggested to develop the simulation

22 accuracy of soil water dynamics and irrigation water use through the OPSIS.

23 Keywords: calibration; irrigation water use; OPSIS; parameterization; soil moisture dynamics; validation

\section{Introduction}

The optimized subsurface irrigation system (OPSIS) is a newly developed subsurface irrigation system to

After that, the outside soil and inside of the pipe come to an equilibrium. This equilibrium controls the amount and 

tool to evaluate the OPSIS. methods.

yield and WUE. However, they suggested conducting further validation of results using different assessment

A crop simulation model is a vital tool with numerous uses, including evaluating different irrigation management practices. A well-calibrated and validated crop model is a fast-alternative option for developing and evaluating agronomic practices (Saseendran et al. 2008). Hence crop models can act as a time and resource-saving option for researches on technological advances in agriculture. Different authors recorded the application of different crop models to evaluate irrigation methods and strategies. (Saseendran et al. 2008) used the CERESmaize model to determine the optimum allocation of limited irrigation between vegetative and reproductive growth stages and optimum soil water depletion level for initiating limited irrigation. (Abd-El-Baki et al. 2017) used a numerical crop model to determine the optimum irrigation depth for the tomato crop. (Kundu et al. 1982) used the CORNGRO crop model to determine the optimum soil moisture depletion and replenishment levels and timing and amount of irrigation during different crop growth stages of corn. (Mubeen et al. 2016) used the CSM-CERESMaize model to optimize the irrigation conditions. (Balwinder-Singh et al. 2016) used APSIM to evaluate mulch's effect on the sowing date and irrigation management of wheat in Central Punjab, India. (Sena et al. 2014) used APSIM to determine the optimum transplanting dates for achieving higher yield and water productivity of ricewheat cropping systems in India's Middle IGP. (Subash et al. 2014) evaluated the different irrigation regimes on rice-wheat cropping systems in IGP using APSIM model. Hence, crop model simulations could be an effective 


\subsection{APSIM}

APSIM (Agricultural Production Systems Simulator) is an open-source (for non-commercial users) crop modeling software, which can use to model the growth and yield of many crops, including sugarcane (Keating et al. 2003; Holzworth et al. 2014). Further, it has modeling functions, which simulate soil water, nutrients, and many more (Inman-Bamber and McGlinchey 2003; Keating et al. 2003; Holzworth et al. 2014; Inman-Bamber et al. 2016). Plant models in APSIM simulate major physiological processes such as phenology, water, and nutrient uptake, development of organs and responses for abiotic stresses, etc. Soil models in APSIM simulate water movements such as infiltration, capillary rise, evaporation, surface runoff, and drainage. Simple tipping bucket approach (SOILWAT module, (Probert et al. 1998)) and comprehensive numerical solution using Richard's equation (SWIM module, (Huth et al. 2012)) use to simulate water and solute movements.

Further, it simulates soil organic matter decomposition and temperature changes (Holzworth et al. 2014). APSIM allows users to incorporate management interventions by their scripts written in scripting languages. Hence, it is a major advantage in APSIM compared to other crop modeling software (Archontoulis et al. 2014; Holzworth et al. 2014). The uncertainties of predictions from the model generally characterized by the error statistics determined from the prediction of experimental data. Therefore, firm parameterization, calibration, and validation need to reduce the uncertainties of predictions.

Therefore, this study aimed to develop the modeling capabilities of APSIM to evaluate the OPSIS. We conducted field experiments and modeling work to parameterize and calibrate the APSIM to simulate sugarcane growth and yield. We conducted field experiments and modeling work to validate the APSIM simulations of yield and growth of sugarcane under our newly developed irrigation method, the optimized subsurface irrigation system 
79 (OPSIS). We evaluated the simulation accuracy of APSIM using different model evaluation criteria during both calibration and validation steps.

\section{Materials and Methods} and Yoshitake 2016).

\subsection{Plant Data}


planting conditions: Spring and Summer planting following Okinawa, Japan's local practice. We started the Spring

99 planting in April 2013 and harvested in March 2014. The crop extended to observe the growth and yield of two consecutive ratoon crops which were harvested in January 2015 and January 2016. We started summer planting in the OPSIS. 
118 using the centrifuge method (Khanzode et al. 1999; ASTM International 2003; Vero et al. 2016). Measured BD

119 and TD values were used to estimate soil saturation. Saturated hydraulic conductivity was estimated in the

120 laboratory using the constant head method (ISTM International 2000). Further, soil samples were analyzed to

121 estimate soil pH, NO3-N, NH4-N levels, and soil carbon. We created a new soil profile for Itoman, Okinawa, and

122 parameterized it using the measured data (Table 1).

123 Table 1. Soil data used to parameterize Itoman soil profile

\begin{tabular}{cccccccc}
\hline Depth & Bulk density & Air Dry & LL15 & DUL & SAT & KS & Sugar LL \\
$(\mathrm{cm})$ & $(\mathrm{g} / \mathrm{cc})$ & $(\mathrm{mm} / \mathrm{mm})$ & $(\mathrm{mm} / \mathrm{mm})$ & $(\mathrm{mm} / \mathrm{mm})$ & $(\mathrm{mm} / \mathrm{mm})$ & $(\mathrm{mm} / \mathrm{day})$ & $(\mathrm{mm} / \mathrm{mm})$ \\
\hline $0-10$ & 1.107 & 0.100 & 0.277 & 0.422 & 0.481 & 7827 & 0.277 \\
$10-20$ & 1.154 & 0.100 & 0.295 & 0.415 & 0.48 & 19712 & 0.295 \\
$20-30$ & 1.310 & 0.100 & 0.298 & 0.453 & 0.484 & 10834 & 0.298 \\
$30-40$ & 1.197 & 0.100 & 0.300 & 0.447 & 0.496 & 4432 & 0.300 \\
$40-50$ & 1.237 & 0.100 & 0.310 & 0.436 & 0.511 & 814 & 0.310 \\
$50-60$ & 1.264 & 0.100 & 0.290 & 0.428 & 0.522 & 800 \\
\hline
\end{tabular}

124 Soil moisture levels were measured in $5,15,25,35,45$, and $55 \mathrm{~cm}$ depths using soil moisture sensors (5TE,

125 Decagon Devices, Pullman, WA, USA) in the OPSIS field to evaluate the soil moisture dynamics of OPSIS. We

126 used first and second ratoons of Spring planting to evaluate the soil moisture dynamics under the OPSIS. 
131 using OPSIS. Flow meters attached to the outlet and inlet of the water column of the OPSIS were used to estimate

132 the daily irrigation amount through the OPSIS. We used first and second ratoons of Spring planting to evaluate the

133 irrigation water use of crops under the OPSIS.

\subsection{Climatological data} humidity values of Naha, Okinawa, Japan were obtained from Japan metrological agency website

137 (www.jma.go.jp/jma/menu/report.html) for the period of $1 / 1 / 1980$ to $31 / 08 / 2016$. Annual average ambient

138 temperature and annual amplitude in mean monthly temperature were calculated using tav_amp utility software of

139 APSIM (https://www.apsim.info/Products/Utilities). A new meteorological was parameterized using the data 140 mentioned above.

\subsection{APSIM-OPSIS module}

143 engine. The fifth layer was selected as the base layer, where the OPSIS is located. The difference between the SAT

144 and the soil water content (SW) of the layer is identified as the input to the layer. The estimated amount of irrigation

145 through the optimized subsurface irrigation is named "opsis (mm/day)." 
149 combines biophysical and management modules within a central engine to simulate diverse cropping systems

150 (Keating et al. 2003; Holzworth et al. 2014). The model is driven by daily climate data and can simulate growth,

151 development, crop yield, and soil interactions.

152 First, we modified the sugar model of APSIM 7.10 by adding a new cultivar, Ni21. Then we parameterize

153 the cultivar parameters using the data obtained from field measurements, published reports on Ni21 cultivar, and

154 experts' views (Table 2).

155 Table 2. Cultivar and plant-specific parameters used to parametrization and calibration of APSIM-Sugar model

Parameter $\quad$ Initial values $\quad$ Values used for simulations

(parameterization) (after calibration)

\begin{tabular}{|c|c|c|c|c|}
\hline \multirow{3}{*}{ Leaf_size $1,14,20$} & Crop & Ratoon & Crop & Ratoon \\
\hline & 2000,48000 & 2000,48000 & 2000,48000 & 2000,48000 \\
\hline & 48000 & 48000 & 48000 & 48000 \\
\hline cane_fraction & 0.7 & 0.65 & 0.7 & 0.7 \\
\hline Sucrose_fraction_stalk $0.2,1$ & $1.0,0.5$ & $1.0,0.5$ & $1.0,0.5$ & $1.0,0.5$ \\
\hline sucrose_delay & 0 & 0 & 0 & 0 \\
\hline min_sstem_sucrose & 800 & 800 & 800 & 800 \\
\hline min_sstem_sucrose_redn & 10 & 10 & 10 & 10 \\
\hline
\end{tabular}




$\begin{array}{ccccc}\text { tt_emerg_to_begcane } & 1800 & 1800 & 1900 & 1900 \\ \text { tt_begcane_to_flowering } & 6000 & 6000 & 6000 & 6000 \\ \text { tt_flowering_to_crop_end } & 2000 & 2000 & 2000 & 2000 \\ \text { green_leaf_no } & 13 & 13 & 13 & 13 \\ \text { tillerf_leaf_size 1, 4, 10, } & 1.5,1.5,1.5,1 & 1.5,1.5,1.5,1 & 1.5,1.5,1.5,1 & 1.5,1.5,1.5,1 \\ \text { rue } & 0,0,1.80,1.80,0,0,1.65,1.65, & 0,0,2.00,2.00, & 0,0,1.85,1.85, \\ & 1.80,0 & 1.65,0 & 2.00,0 & 1.85,0 \\ \text { Crop_height_max } & 6000 & 6000 & 4000 & 4000\end{array}$

157 irrigation from March 2013 to January 2016 and September 2013 to January 2015, respectively. As APSIM

158 underestimated the growth and yield, we modified the RUE like-minded (Gunarathna et al. 2019) and (Sexton et

159 al. 2017). (Dias et al. 2019) also suggested substantial changes to enable APSIM-Sugar to simulate canopy and

160 yield of Brazilian genotypes. We increased the maximum RUE values up to 2.0, confining the findings of (Muchow

161 et al. 1997; De Silva and De Costa 2012). Similarly, we increased the maximum RUE values of ratoon crop up

162 to 1.85 , conforming to the gap maintained by APSIM. As Ni21 is developed to withstanding typhoon conditions,

163 plants usually do not show higher plant heights. Hence, we limited the maximum plant height up to $4000 \mathrm{~mm}$ from

164 the default of $6000 \mathrm{~mm}$. Further, we calibrated cane fraction (CF) and thermal time from emergence to beginning

165 of cane (EB) by trial and error method to find the optimum values for those parameters (Table 2). 
168 harvesting, plant heights of first ratoon crop of spring-plant and main crop of summer-plant, soil moisture levels

169 of top five layers and irrigation water use through the OPSIS to validate the application of APSIM with OPSIS.

170 During the summer of 2015, several typhoons occurred, and substantial crop damages were observed. Therefore,

171 after considering the field observations, historical yield records, and experts' views, the observed yield of the

172 second ratoon of spring plants (both sprinkler and OPSIS irrigated crops) and the first ratoon of summer plants

173 were adjusted, adding $20 \%$ of observed yield to the observed yield.

\subsection{Model Evaluation}

We used different model evaluation criteria such as root mean square error (RMSE; Equation 1), mean

176 absolute error (MAE; Equation 2), coefficient of determination ( $\mathrm{R}^{2}$; Equation 3), and Wilmott's agreement index

177 (d; Equation 4) (Willmott 1981) to evaluate the simulation accuracy (Krause et al. 2005; Dias and Sentelhas 2017).

178 Low RMSE and MAE values indicate good agreement between model outputs and observed values, while high $\mathrm{R}^{2}$

179 and d also assure the same. The Lin's concordance correlation coefficient (CCC) integrates precision through

180 Pearson's correlation coefficient, which represents the proportion of the total variance in the observed data that can

181 be explained by the model, and accuracy by a bias which indicates how far the regression line deviates from the

182 concordance line (Ojeda et al. 2017). CCC ranges from -1 to 1, with a perfect agreement at 1 . It can legitimately

183 calculate accuracy with few observations for agreement on a continuous measure obtained by two methods

184 (Stevenson et al. 2018). We calculated the CCC using epiR package (Stevenson et al. 2018) of R software (R Core

185 Team 2018).

186

$\operatorname{RMSE}=\sqrt{\frac{1}{n} \sum_{\mathrm{i}=1}^{\mathrm{n}}\left(\mathrm{S}_{\mathrm{i}}-\mathrm{O}_{\mathrm{i}}\right)^{2}}$ 


$$
R^{2}=\left[\frac{\sum_{i=1}^{n}\left(o_{i}-\bar{O}\right)\left(S_{i}-\bar{S}\right)}{\sqrt{\sum_{i=1}^{n}\left(o_{i}-\bar{O}\right)^{2}} \sqrt{\sum_{i=1}^{n}\left(S_{i}-\bar{S}\right)^{2}}}\right]^{2}
$$

$$
d=1-\frac{\sum_{i=1}^{n}\left(S_{i}-O_{i}\right)^{2}}{\sum_{i=1}^{n}\left(\left|S_{i}-\bar{O}\right|+\left|o_{i}-\bar{O}\right|\right)^{2}}
$$

where, $S_{i}$ and $O_{i}$ are the simulated and observed value of the parameter (in fresh cane yield (t/ha), plant height and observed values, respectively; and $\mathrm{n}$ is the number of observations.

\section{Results and Discussion}

\subsection{Parameterization and calibration of APSIM-Sugar to simulate growth and yield of cultivar Ni21}


simulate the millable stalk weight $\left(\mathrm{R}^{2}=0.72, \mathrm{RMSD}=1.94 \mathrm{t} / \mathrm{ha}\right)$ with fairly good accuracy. (Inman-Bamber et al.

208 and root water supply. Our study also proves the virtuous ability of APSIM-Sugar to simulate fresh cane weight

209 as all model evaluation criteria show a good fit between simulations and observations $\left(\mathrm{RMSE}=3.195 \mathrm{t} / \mathrm{ha}, \mathrm{R}^{2}=\right.$

$2100.93, \mathrm{MAE}=2.74 \mathrm{t} / \mathrm{ha}$ ). Further, plant height simulations, also showed good agreement with the observations

$211 \quad\left(\mathrm{RMSE}=493 \mathrm{~mm}, \mathrm{R}^{2}=0.87, \mathrm{MAE}=397 \mathrm{~mm}\right)$.
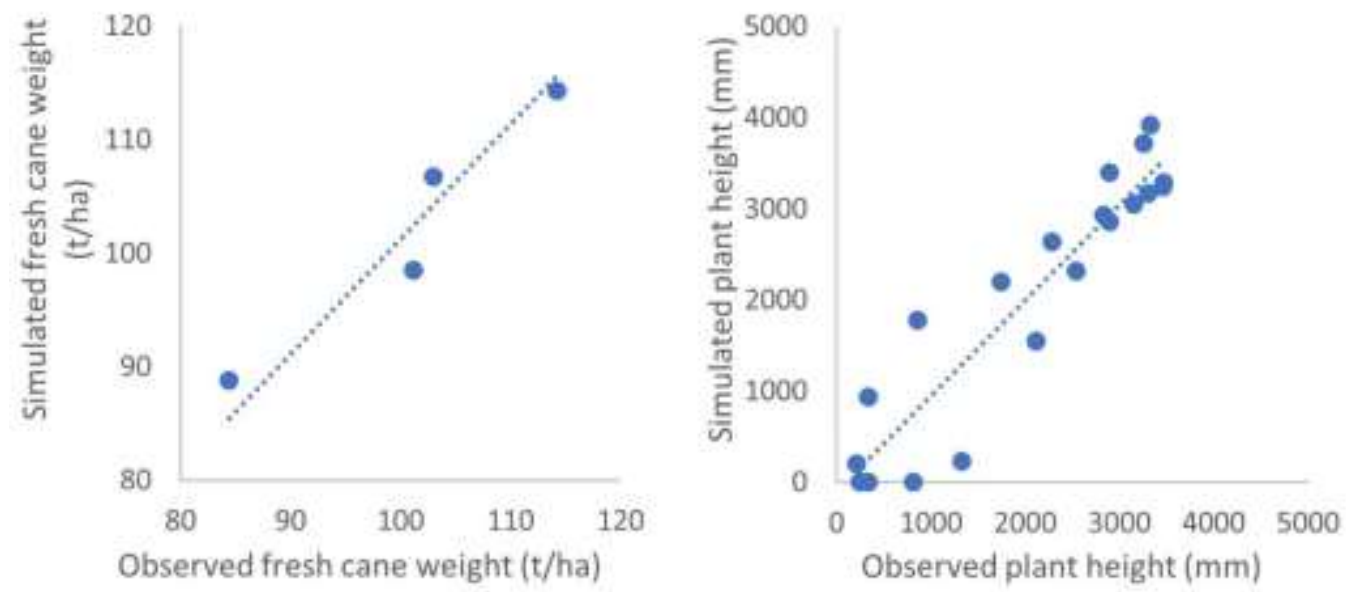

Figure 1. Observed versus simulated a) fresh cane weight; b) plant height of sugarcane cultivar Ni21

217 APSIM may not always use the maximum RUE values as it is always controlled by soil moisture status, nutrient

218 availability, and reduced growth phenomenon (RGP) (Park et al. 2005). RGP reduces RUE, with highly favorable

219 environment conditions as highly favorable conditions may lead to lodging (Park et al. 2005; van Heerden et al. 
223 parameterized and calibrated APSIM-sugar model and APSIM-OPSIS module. Results revealed that APSIM

224 simulations show good agreement with observed fresh cane yield and plant height. Further, observed soil moisture

225 dynamics and irrigation water use also showed acceptable agreement between simulated values.

\section{3.2.1 Plant height}

228 Although it was slightly underestimated during the latter part, model evaluation criteria confirmed that simulation

229 is almost like the observations (Table 3). The first ratoon of spring-plant showed variation between observed and

230 simulated plant heights as APSIM sugarcane under simulated plant height in the crop's early stages (Figure 3).

231 However, in the late stages, the first ratoon of the spring plant showed a higher growth rate in simulation than the

232 observed; therefore, during the harvesting, simulated plant height became slightly higher (4\%) than the observed

233 value. Although the simulation accuracy is not good as the summer plant, model evaluation criteria confirmed that

234 simulation is comparable with observations (Table 3). Further, Table 3 confirmed that the plant height simulation

235 of the summer-planted main crop is better than the calibration study results, while the first ratoon crop of spring-

236 plant showed slightly poor performances compared to the calibration results. 

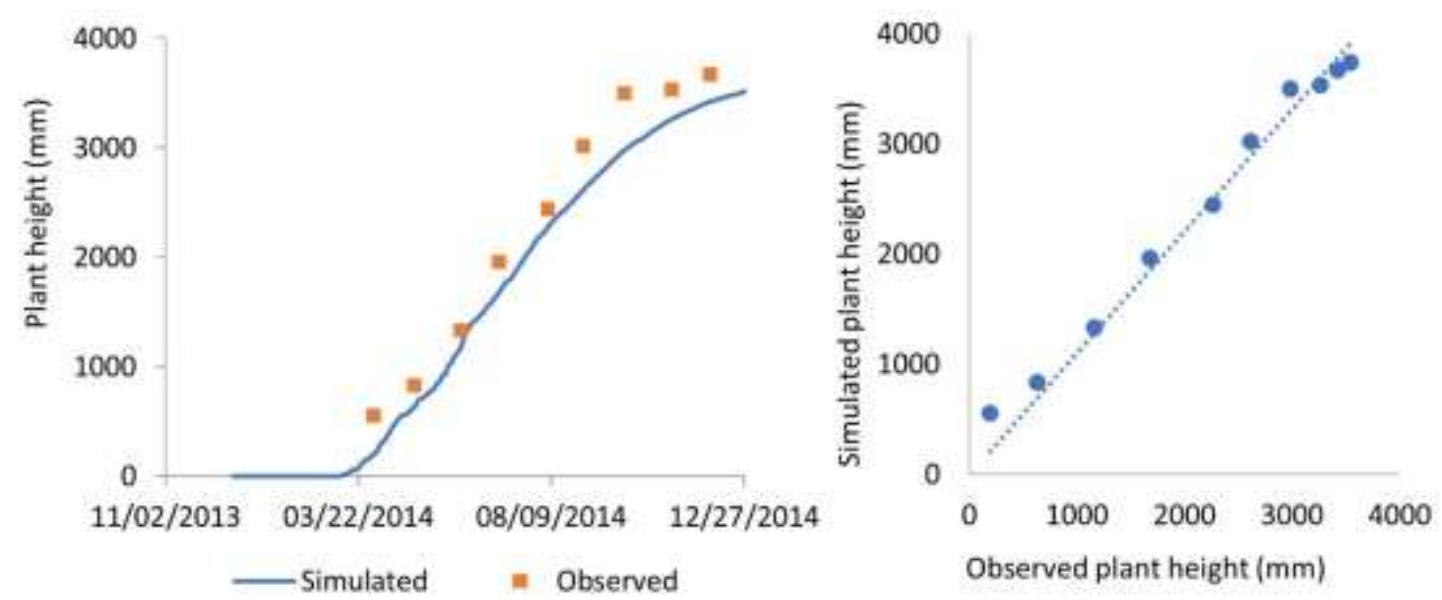

Figure 2. Observed versus simulated plant height of summer planted sugarcane crop
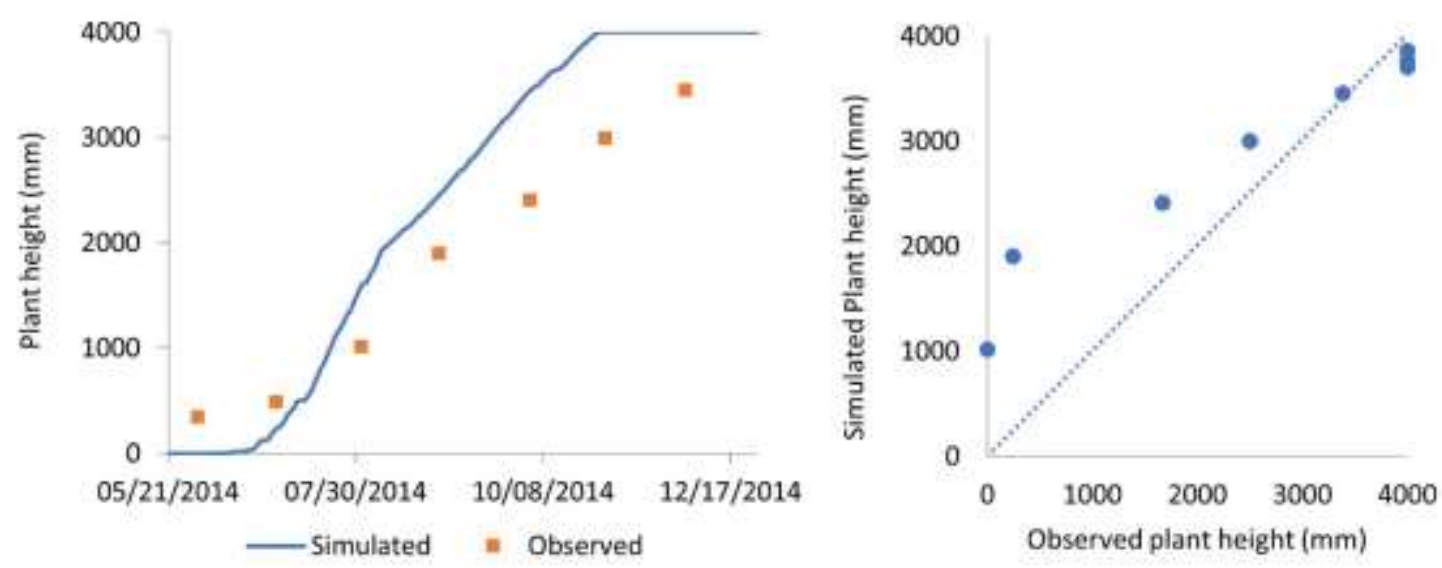

Figure 3. Observed versus simulated plant height of spring planted first ratoon crop

241 Table 3. Evaluation of simulation accuracy of APSIM with OPSIS

\begin{tabular}{|c|c|c|c|c|c|c|}
\hline \multirow{2}{*}{ Variable (unit) } & \multirow{2}{*}{$\begin{array}{l}\text { Planting season } \\
\text { (Crop/ratoon) }\end{array}$} & \multicolumn{5}{|c|}{ Model evaluation criterion } \\
\hline & & $\mathrm{R}^{2}$ & *MAE & *RMSE & $\mathrm{d}$ & $\mathrm{CCC}$ \\
\hline Fresh cane yield (t/ha) & All & 0.82 & 4.67 & 6.08 & 0.64 & 0.56 \\
\hline Plant height (mm) & Summer planting (Crop) & 0.99 & 286 & 306 & 0.98 & 0.97 \\
\hline
\end{tabular}




\begin{tabular}{|c|c|c|c|c|c|c|}
\hline & Spring planting ( $1^{\text {st }}$ ratoon $)$ & 0.96 & 582 & 769 & 0.91 & 0.85 \\
\hline Average soil moisture of & Spring planting ( $1^{\text {st }}$ ratoon $)$ & 0.32 & 0.047 & 0.052 & 0.49 & 0.16 \\
\hline root zone $(\mathrm{mm} / \mathrm{mm})$ & Spring planting ( $2^{\text {nd }}$ ratoon $)$ & 0.50 & 0.053 & 0.056 & 0.45 & 0.15 \\
\hline Monthly irrigation water & Spring planting ( $1^{\text {st }}$ ratoon $)$ & 0.01 & 11.19 & 13.18 & 0.47 & 0.07 \\
\hline use (mm/month) & Spring planting ( $2^{\text {nd }}$ ratoon) & 0.22 & 15.51 & 17.45 & 0.27 & 0.39 \\
\hline
\end{tabular}

$242 *$ Unit is equal to the unit of the variable

\section{$243 \quad$ 3.2.2 Fresh cane weight}

244 Confirming the virtuous ability of APSIM to simulate fresh cane weight, APSIM under OPSIS simulated

245 fresh cane yield with good agreement to the observations (Figure 4) as all model evaluation criteria shows a good

246 fit between simulations and observations (Table 3). The RMSE value reported (6.08 t/ha) is far enough for a

247 simulation study as it is about $5 \%$ of the average observed fresh cane yield. $\mathrm{R}^{2}(0.82)$ and $\mathrm{d}(0.64)$ also confirmed

248 the goodness of fit between observed and simulated fresh cane yield. Further, these validation results are equally

249 good as the results of the calibration study. Similarly, (Mao et al. 2018) showed the ability of locally calibrated

250 APSIM-sugar to simulate cane yield with a high accuracy level. 


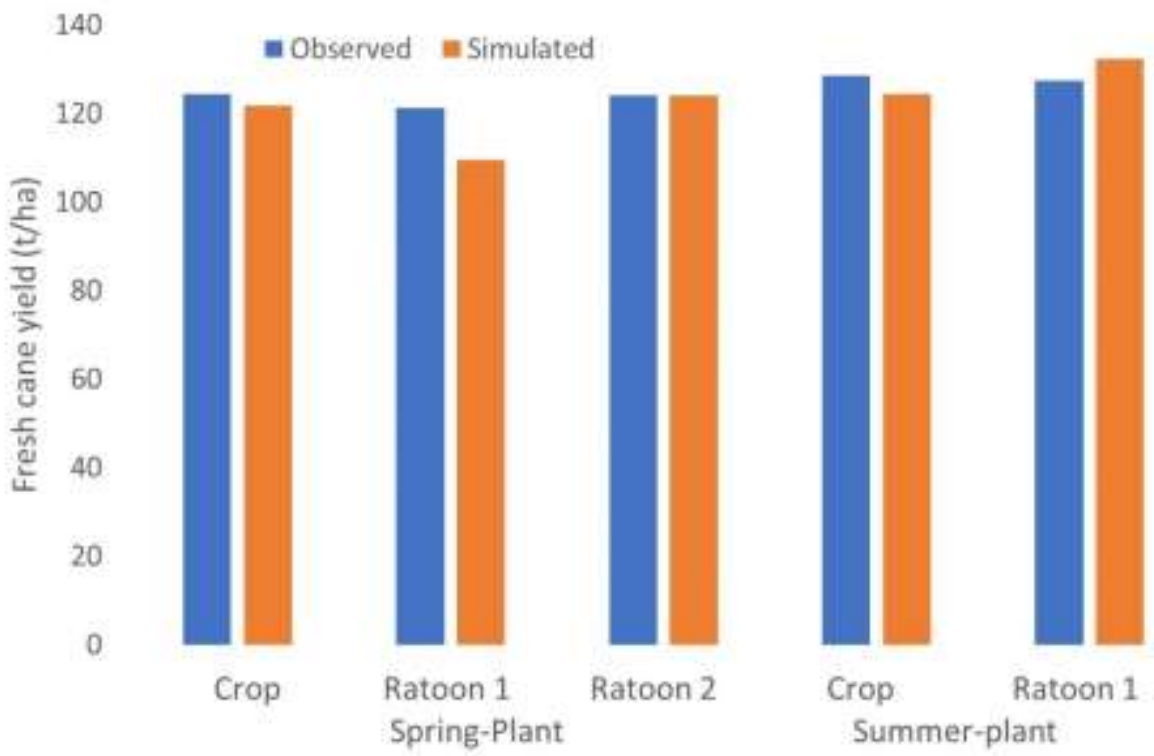

Figure 4. Comparison of observed and simulated yield of sugarcane under OPSIS

\subsubsection{Soil moisture dynamics}

255 first and second ratoons of spring planting. The results showed that APSIM had overpredicted the soil moisture

256 levels, especially the root zone's upper part. Since the soil water movements are much complicated, it is difficult

257 to acquire precise simulations from simple model predictions. In this study, we used a cascading layer approach

258 to estimate the soil water movements. However, this is a simple approach; hence, it may not accurately simulate 


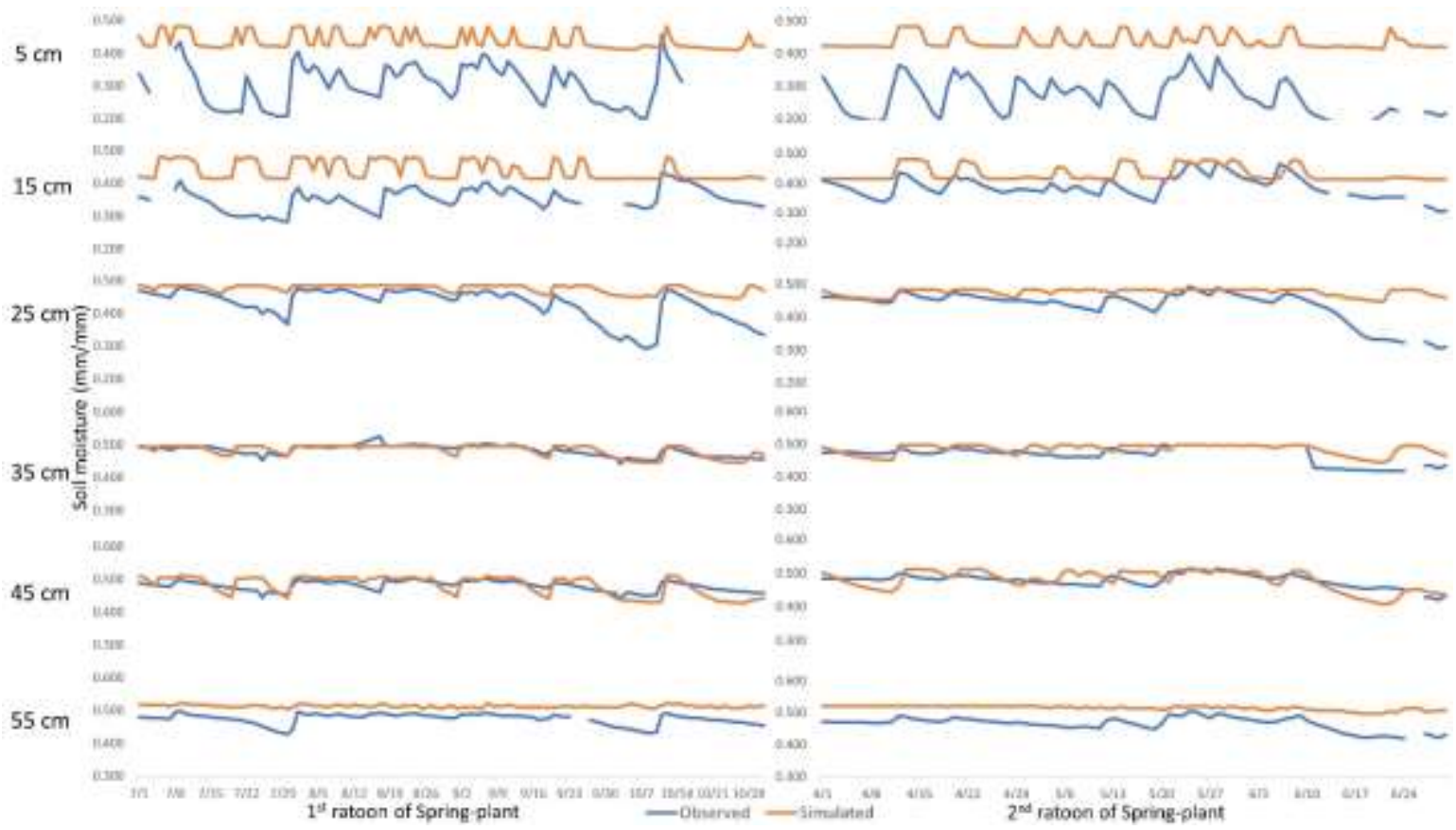

Figure 5. Observed and simulated soil moisture variation different layers of the soil during the first and second 
277 therefore, we cannot use this model. This model may able to comprehend the soil moisture dynamics of OPSIS

278 irrigated fields. Therefore, we are suggesting studying the applicability of this model in future studies.

\section{$279 \quad 3.2 .4$ Irrigation water use}

284 this study, we simulated the irrigation water use applied through our newly designed irrigation system named

285 OPSIS. Model evaluation criteria (Table 3) show that the simulations are not comparable with the observed

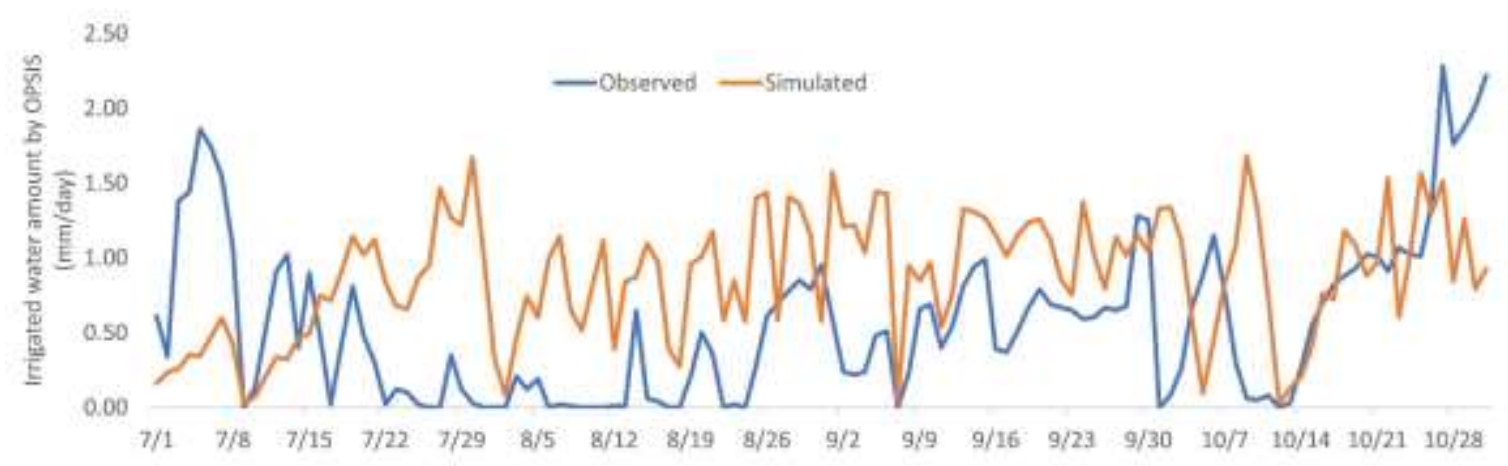




\section{Conclusions and Recommendations}

We modified the APSIM-Sugar model to simulate the growth and yield of sugarcane cultivar Ni21, which was developed to withstand typhoons' strong winds. Then we parameterize the cultivar Ni21 using measured values, information published in reports, and expert's views. However, APSIM underestimated the growth and yield of sugarcane cultivar Ni21 under Okinawan conditions. Therefore, the APSIM-Sugar model was modified and calibrated using radiation use efficiency, thermal time from emergence to the beginning of cane and cane fraction. After the calibration, APSIM simulations showed a close relationship with the observations. Then, we validated the APSIM to use with OPSIS. We developed the APSIM-OPSIS module to couple OPSIS with the APSIM engine. The simulation results were agreed with the observations. Simulated plant height and fresh cane yield showed good agreement with the observations. However, APSIM showed overestimation for soil water content in upper soil layers and irrigation water use of OPSIS.

Hence, the newly developed APSIM-OPSIS module can successfully simulate the crop growth and yield of sugarcane with an optimized subsurface irrigation system. Although it gives good results, further studies are suggested to develop the simulation accuracy of soil water dynamics and irrigation water use through the OPSIS.

Funding: This research received no external funding.

Acknowledgments: Authors acknowledge the ownership of experimental data of Itoman field research carried out by Paddy Research CO., LTD, Land Improvement District, and University of the Ryukyus. 
Conflicts of Interest: The authors declare no conflict of interest.

314 The use of plant materials: Sugarcane cultivar Ni21 that we used in the present experiment was transferred from

315 National Agricultural Research Organization (NARO) to the Itoman experimental field of Paddy Research CO.,

316 LTD by the Joint Research Contract of Paddy Research CO., LTD, Land Improvement District, and University of

317 the Ryukyus, and the experiment was conducted by compiling with the guideline and regulation of this contract.

\section{References}

Abd-El-Baki, Hassan M, Haruyuki Fujimaki, Ieyasu Tokumoto, and Tadaomi Saito. 2017. Determination of irrigation depths using a numerical model of crop growth and quantitative weather forecast and evaluation of its effect through a field experiment for potato 24 .

Archontoulis, Sotirios V., Fernando E. Miguez, and Kenneth J. Moore. 2014. Evaluating APSIM maize, soil water, soil nitrogen, manure, and soil temperature modules in the Midwestern United States. Agronomy Journal 106: 1025-1040. https://doi.org/10.2134/agronj2013.0421.

ASTM International. 2003. Standard Test Methods for Determination of the Soil Water Chararcteristic Curve for Desorption Using a Hanging Column, Pressure Extractor, Chilled Mirror Hygrometer, and/or Centrifuge. Vol. D 6836-0. 
B.V. https://doi.org/10.1016/j.fcr.2011.04.016.

Balwinder-Singh, E. Humphreys, D. S. Gaydon, and P. L. Eberbach. 2016. Evaluation of the effects of mulch on optimum sowing date and irrigation management of zero till wheat in central Punjab, India using APSIM. Field Crops Research 197. Elsevier B.V.: 83-96. https://doi.org/10.1016/j.fcr.2016.08.016.

Brown, Hamish, Sam Carrick, Karin Müller, Steve Thomas, Joanna Sharp, Rogerio Cichota, Dean Holzworth, and Brent Clothier. 2018. Modelling soil-water dynamics in the rootzone of structured and water-repellent soils. Computers and Geosciences 113. Elsevier Ltd: 33-42. https://doi.org/10.1016/j.cageo.2018.01.014.

Cheeroo-Nayamuth, F. C., M. J. Robertson, M. K. Wegener, and A. R H Nayamuth. 2000. Using a simulation model to assess potential and attainable sugar cane yield in Mauritius. Field Crops Research 66: $225-243$. https://doi.org/10.1016/S0378-4290(00)00069-1.

Dias, Henrique Boriolo, Geoff Inman-Bamber, Rodrigo Bermejo, Paulo Cesar Sentelhas, and Diomedes Christodoulou. 2019. New APSIM-Sugar features and parameters required to account for high sugarcane yields in tropical environments. Field Crops Research 235. Elsevier: 38-53. https://doi.org/10.1016/j.fcr.2019.02.002.

Dias, Henrique Boriolo, and Paulo Cesar Sentelhas. 2017. Evaluation of three sugarcane simulation models and their ensemble for yield estimation in commercially managed fields. Field Crops Research 213. Elsevier: 174-185. https://doi.org/10.1016/j.fcr.2017.07.022.

Gima, Hiroki, and Tsuyoshi Yoshitake. 2016. A Comparative Study of Energy Security in Okinawa Prefecture and the State of Hawaii. Evergreen: Joint Journal of Novel Carbon Resource Sciences \& Green Asia Strategy 3: 36-44. https://doi.org/https://doi.org/10.5109/1800870. 
Gunarathna, M.H.J.P., Kazuhito Sakai, Tamotsu Nakandakari, Momii Kazuro, Tsuneo Onodera, Hiroyuki Kaneshiro, Hiroshi Uehara, and Kousuke Wakasugi. 2017. Optimized Subsurface Irrigation System (OPSIS): Beyond Traditional Subsurface Irrigation. Water 9: 599. https://doi.org/10.3390/w9080599.

Gunarathna, M.H.J.P., Kazuhito Sakai, Tamotsu Nakandakari, Kazuro Momii, and M.K.N. Kumari. 2019. Sensitivity Analysis of Plant- and Cultivar-Specific Parameters of APSIM-Sugar Model : Variation between Climates and Management Conditions. Agronomy 9: 242. https://doi.org/https://doi.org/10.3390/agronomy9050242.

Gunarathna, M.H.J.P., Kazuhito Sakai, Tamotsu Nakandakari, Kazuro Momii, Tsuneo Onodera, Hiroyuki Kaneshiro, Hiroshi Uehara, and Kousuke Wakasugi. 2018. Optimized subsurface irrigation system: The future of sugarcane irrigation. Water 10: 314. https://doi.org/10.3390/w10030314.

van Heerden, P. D.R., A. Singels, A. Paraskevopoulos, and R. Rossler. 2015. Negative effects of lodging on irrigated sugarcane productivity-An experimental and crop modelling assessment. Field Crops Research. https://doi.org/10.1016/j.fcr.2015.05.019.

Holzworth, Dean P., Neil I. Huth, Peter G. deVoil, Eric J. Zurcher, Neville I. Herrmann, Greg McLean, Karine Chenu, et al. 2014. APSIM - Evolution towards a new generation of agricultural systems simulation. Environmental Modelling and Software 62. Elsevier Ltd: 327-350. https://doi.org/10.1016/j.envsoft.2014.07.009.

Huth, N I, K L Bristow, and K Verburg. 2012. SWIM3: Model use, Calibration and Validation. Transactions of the ASABE 55: 1303-1313. 
for water-limited environments: Enhanced capability of the APSIM sugarcane model for assessing traits for https://doi.org/10.1016/j.fcr.2016.06.013.

Inman-Bamber, N. G., and M. G. McGlinchey. 2003. Crop coefficients and water-use estimates for sugarcane based on long-term bowen ratio energy balance measurements. Field Crops Research 83: 125-138. https://doi.org/10.1016/S0378-4290(03)00069-8.

ISTM International. 2000. Standard Test Method for Permeability of Granular Soils (Constant Head). ASTM: D $2434-68$.

Keating, B. A., P. S. Carberry, G. L. Hammer, M. E. Probert, M. J. Robertson, D. Holzworth, N. I. Huth, et al. Agronomy 18: 267-288. https://doi.org/10.1016/S1161-0301(02)00108-9.

Keating, B A, M J Robertson, R C Muchow, and N I Huth. 1999. Modelling sugarcane production systems I. Development and performance of the sugarcane module. Field Crops Research 61: 253-271.

Khanzode, R M, Delwyn G Fredlund, and Sai K Vanapalli. 1999. An alternative method for the measurement of soil-water characteristic curve for fine-grained soils. In Proceedings of the 52nd Canadian Geotechnical

Krause, P, D P Boyle, and F Bäse. 2005. Advances in Geosciences Comparison of different efficiency criteria for hydrological model assessment. Advances in Geosciences 5: 89-97. https://doi.org/10.5194/adgeo-5-89Conference, Regina, Saskatchewan., 623-630. 
Mao, J., N.G. Inman-Bamber, X. Lu, P.A. Jackson, J. Wang, J. Liu, and Y. Fan. 2018. Adaptability of APSIM-

Marin, Fábio R, James W Jones, Federick Royce, Carlos Suguitani, L Jorge, Wander Pallone Filho, and Daniel S

P Nassif. 2011. Parameterization and Evaluation of Predictions of DSSAT/Canegro for Brazilian Sugarcane. In Apresentado no XVII Congresso Brasileiro de Agrometeorologia, - 18 a 21 de Julho de 2011, 1-5.

Mubeen, Muhammad, Ashfaq Ahmad, Aftab Wajid, Tasneem Khaliq, Hafiz Mohkum Hammad, Syeda Refat Sultana, Shakeel Ahmad, Shah Fahad, and Wajid Nasim. 2016. Application of CSM-CERES-maize model in optimizing irrigated conditions. Outlook on Agriculture 45: 173-184. https://doi.org/10.1177/0030727016664464.

Muchow, Russell C, Carl I Evensen, Robert V Osgood, and Michael J Robertson. 1997. Yield Accumulation in Irrigated Sugarcane: II. Utilization of Intercepted Radiation. Agronomy Journal 89. Madison, WI: American Society of Agronomy: 646-652. https://doi.org/10.2134/agronj1997.00021962008900040017x. Evaluation of Agricultural Production Systems Simulator as yield predictor of Panicum virgatum and Miscanthus $\mathrm{x}$ giganteus in several US environments. GCB Bioenergy 9: 796-816. https://doi.org/10.1111/gcbb.12384. 
under high input conditions. Field Crops Research 92: 305-320. https://doi.org/10.1016/j.fcr.2005.01.025.

412

413

414

415

416

417

418

420

Probert, M. E., J. P. Dimes, B. A. Keating, R. C. Dalal, and W. M. Strong. 1998. APSIM's water and nitrogen modules and simulation of the dynamics of water and nitrogen in fallow systems. Agricultural Systems 56: 1-28. https://doi.org/10.1016/S0308-521X(97)00028-0.

R Core Team. 2018. R: A language and environment for statistical computing. R Foundation for Statistical Computing, Vienna, Austria. URL https://www.R-project.org/.

Rubel, Franz, and Markus Kottek. 2010. Observed and projected climate shifts 1901-2100 depicted by world maps of the Köppen-Geiger climate classification. Meteorologische Zeitschrift 19: 135-141. https://doi.org/10.1127/0941-2948/2010/0430.

Saseendran, S. A., L. R. Ahuja, D. C. Nielsen, T. J. Trout, and L. Ma. 2008. Use of crop simulation models to evaluate limited irrigation management options for corn in a semiarid environment. Water Resources Research 44: 1-12. https://doi.org/10.1029/2007WR006181.

Sena, D R, Central Soil, Ramesh Kumar Yadav, Pk Mishra, Water Conservation, and Satyendra Kumar. 2014. Simulating the Effect of Transplanting Dates and Irrigation Schedules on Water Productivity of Irrigated Rice in Upper IGP using The APSIM Model Simulating the Effect of Transplanting Dates and Irrigation Schedules on Water Productivity of Irrigated Rice. In SAC Monograph: The SAARC-Australia ProjectDeveloping Capacity in Cropping Systems Modelling for South Asia, ed. D. S. Gaydon, I. Md Saiyed, and C. Roth, 87-103. SAARC Agriculture Centre.

Sexton, J., Y. L. Everingham, and G. Inman-Bamber. 2017. A global sensitivity analysis of cultivar trait parameters in a sugarcane growth model for contrasting production environments in Queensland, Australia. European 
De Silva, A. L.C., and W. A.J.M. De Costa. 2012. Growth and Radiation Use Efficiency of Sugarcane Under 012-0148-y.

de Sousa, Robson Thiago Xavier, Gaspar Henrique Korndörfer, Rogério Augusto Brem Soares, and Patrícia Rezende Fontoura. 2015. Phosphate Fertilizers for Sugarcane Used at Pre-Planting (Phosphorus Fertilizer Application). Journal of Plant Nutrition 38: 1444-1455. https://doi.org/10.1080/01904167.2014.990567. et al. 2018. epiR: Tools for the Analysis of Epidemiological Data. Irrigation Regimes on Rice-Wheat Cropping System in the Upper-Gangetic Plains of India using APSIM. In SAC Monograph: The SAARC-Australia Project-Developing Capacity in Cropping Systems Modelling for South Asia, ed. D. S. Gaydon, I. Md Saiyed, and C. Roth, 104. SAARC Agriculture Centre. G. Richards, and Owen Fenton. 2016. A methodological framework to determine optimum durations for the construction of soil water characteristic curves using centrifugation. Irish Journal of Agricultural and Food 
Figures
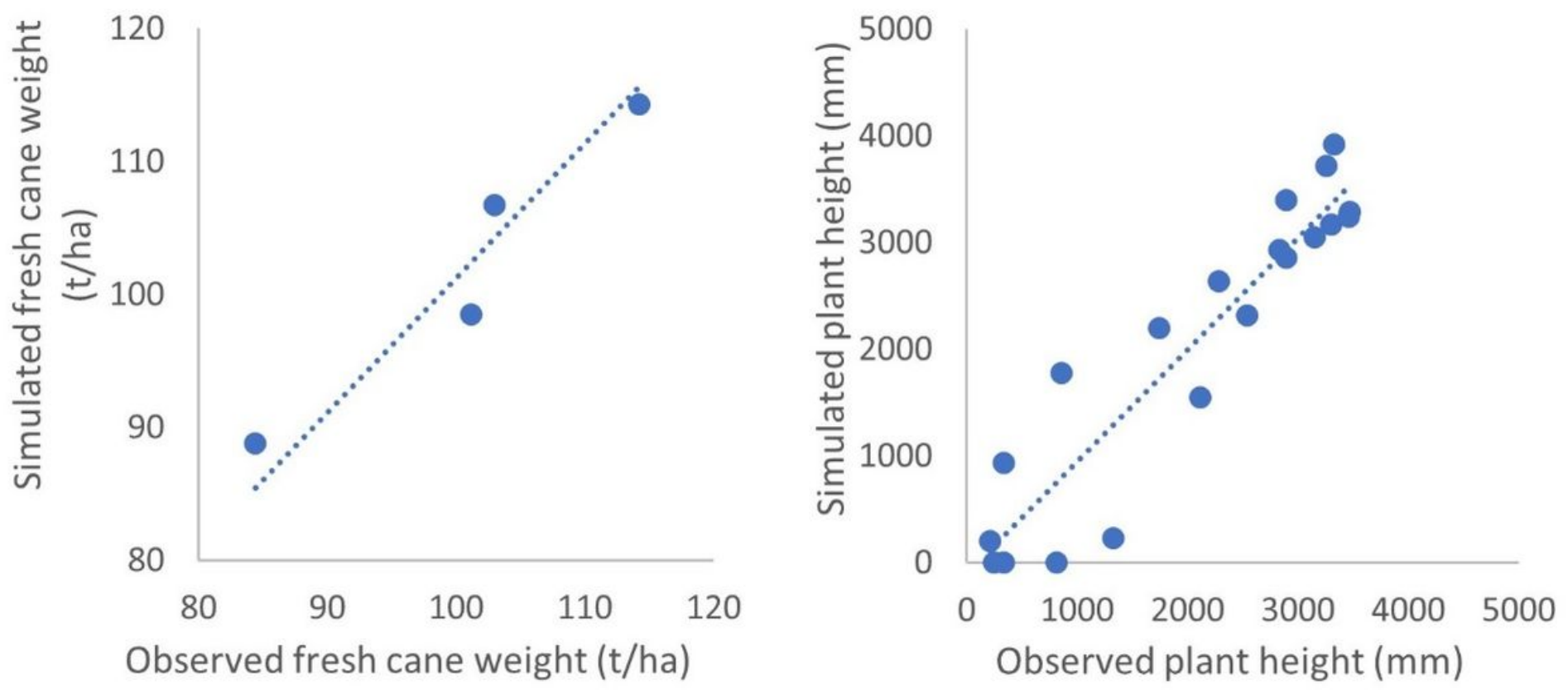

Figure 1

Observed versus simulated a) fresh cane weight; b) plant height of sugarcane cultivar Ni21
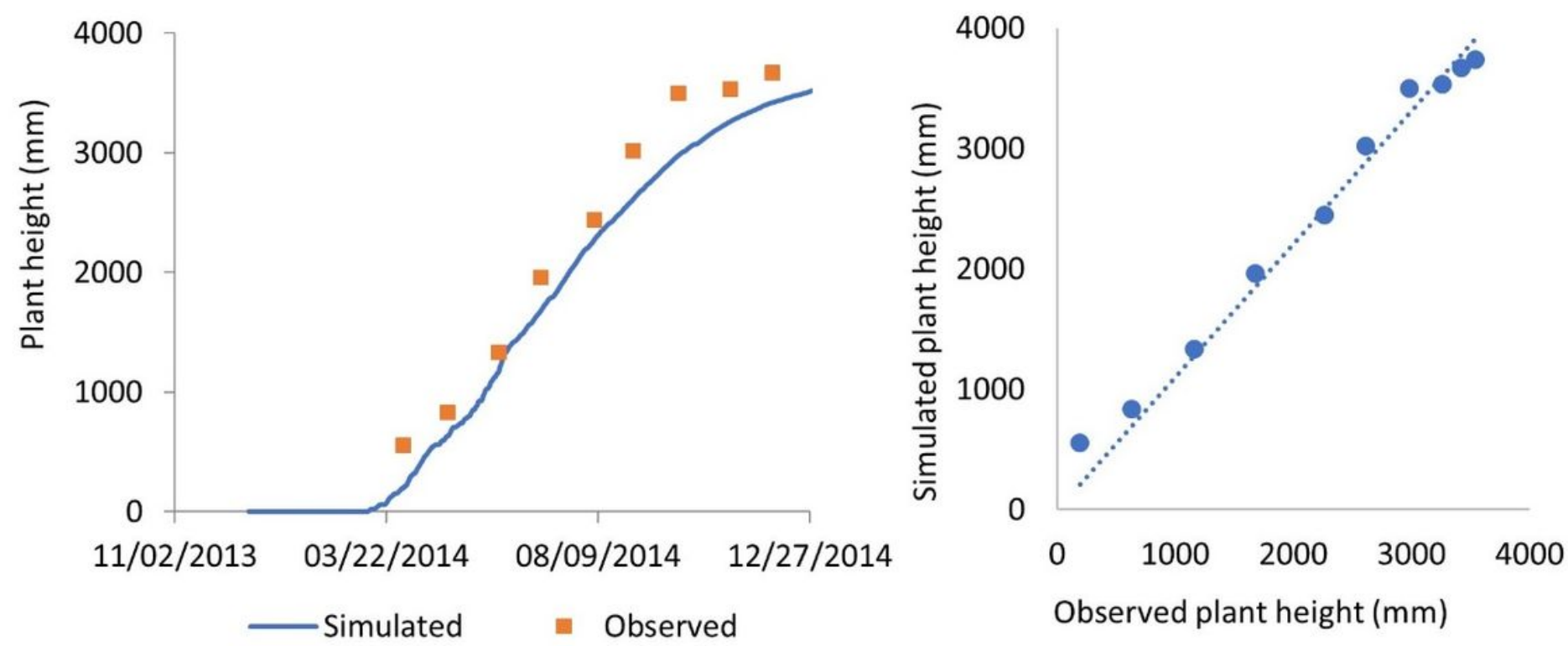

Figure 2

Observed versus simulated plant height of summer planted sugarcane crop 

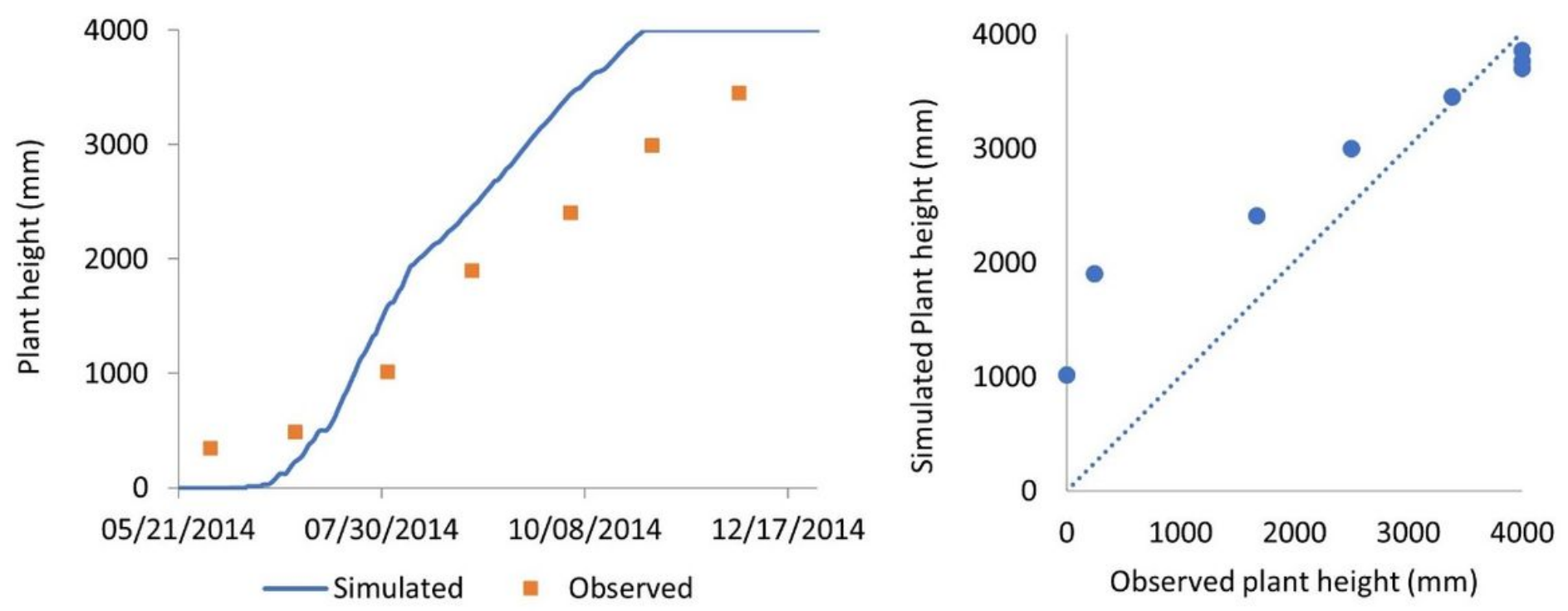

Figure 3

Observed versus simulated plant height of spring planted first ratoon crop

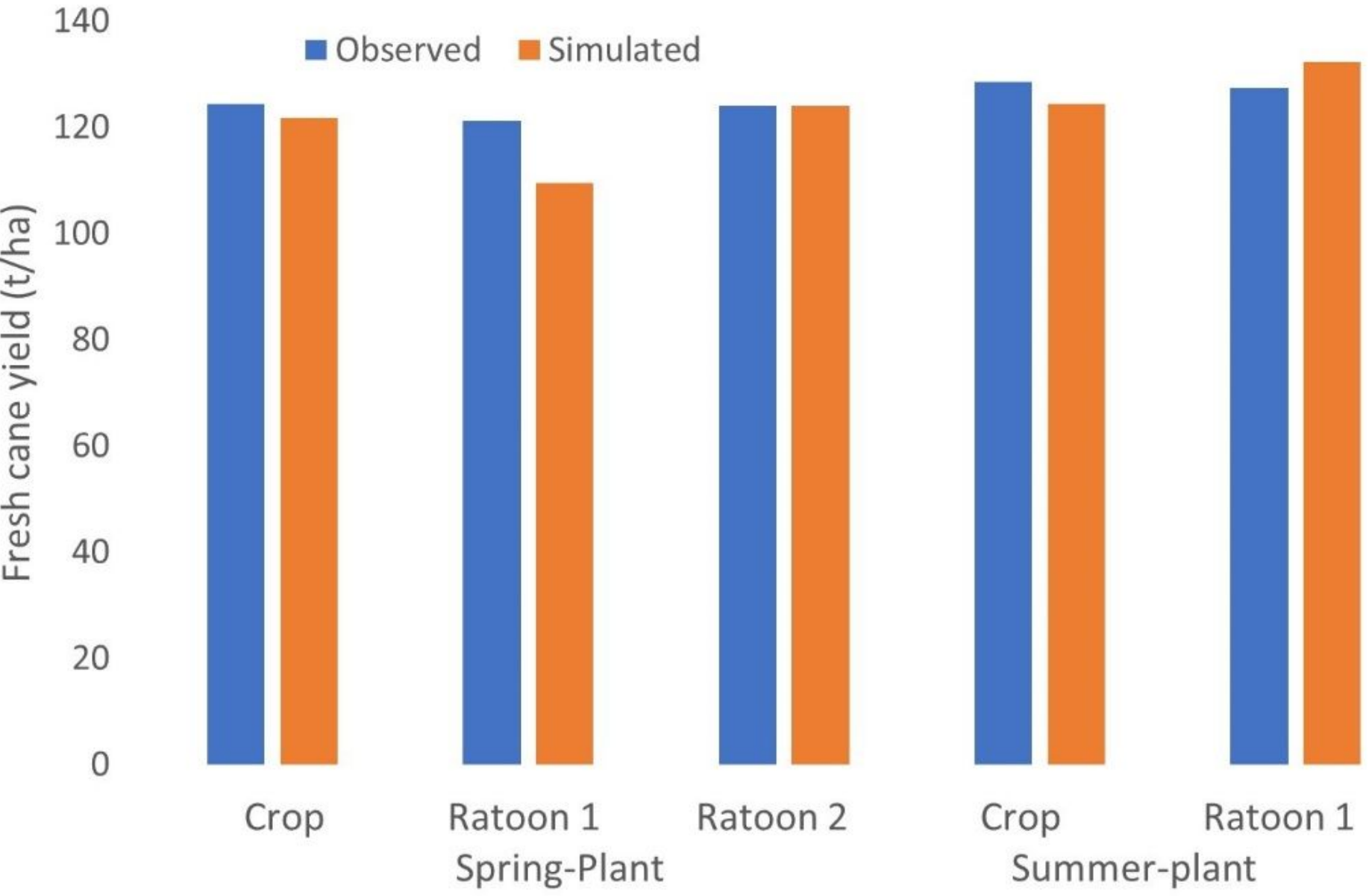

Figure 4

Comparison of observed and simulated yield of sugarcane under OPSIS 


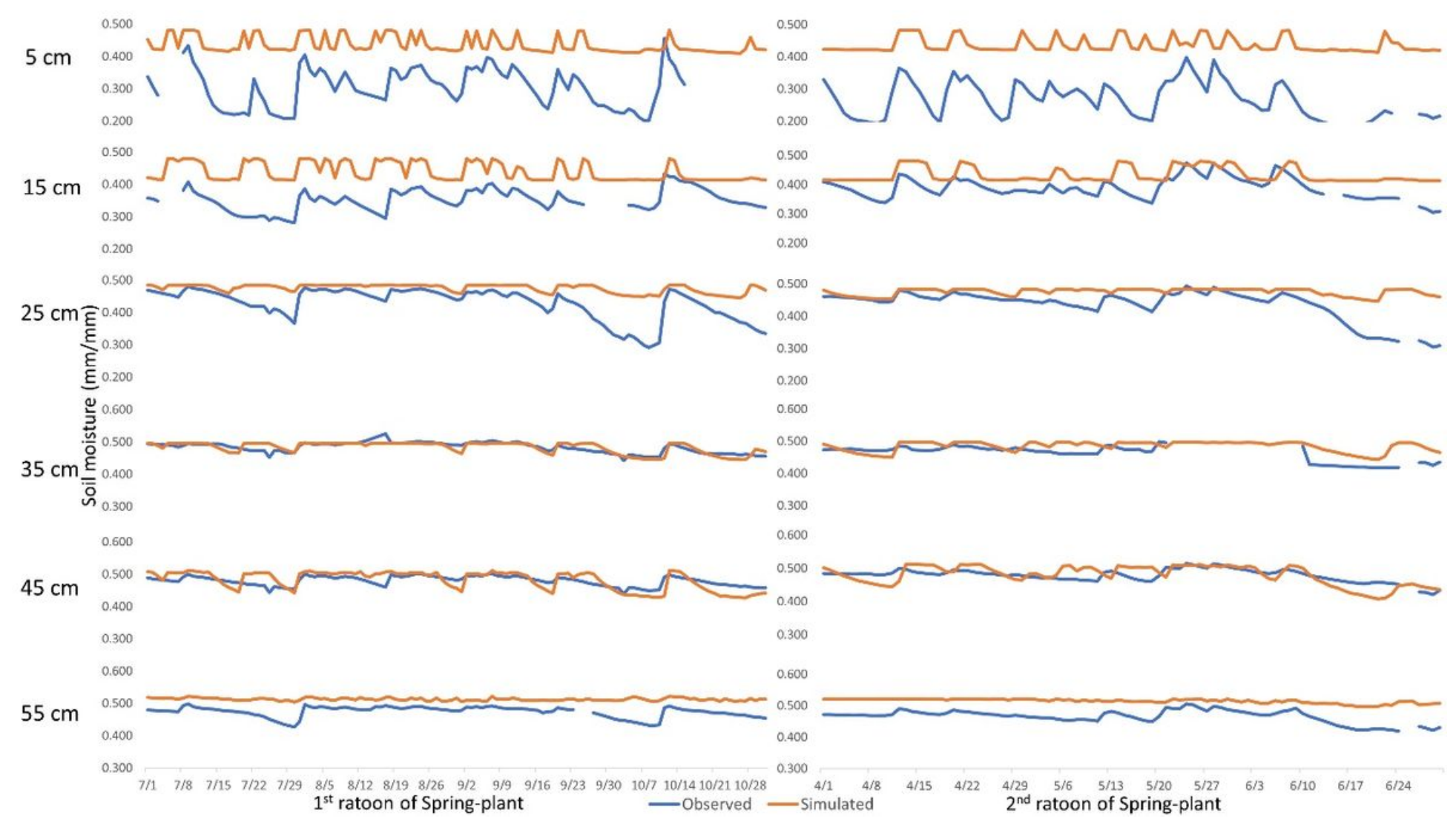

Figure 5

Observed and simulated soil moisture variation different layers of the soil during the first and second ratoon crop of spring planting

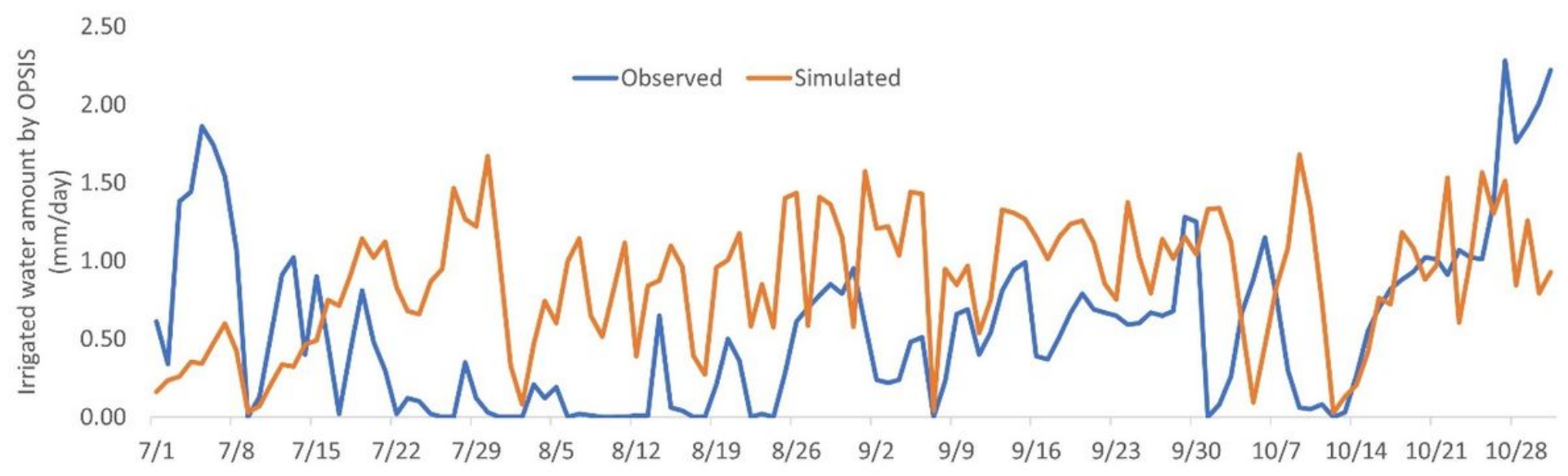

\section{Figure 6}

Observed versus simulated irrigation water use through OPSIS of spring-planted first ratoon crop 